\title{
Métis Women's Experiences in Canadian Higher Education
}

\author{
Bryanna Scott
}

\author{
Faculty of Education, Lakehead University, Thunder Bay, ON P7B 5E1, Canada; brscott@lakeheadu.ca
}

Citation: Scott, Bryanna. 2021. Métis Women's Experiences in Canadian Higher Education. Genealogy 5: 49. https://doi.org/10.3390/ genealogy5020049

Received: 2 March 2021

Accepted: 3 May 2021

Published: 14 May 2021

Publisher's Note: MDPI stays neutral with regard to jurisdictional claims in published maps and institutional affiliations.

Copyright: (C) 2021 by the author. Licensee MDPI, Basel, Switzerland. This article is an open access article distributed under the terms and conditions of the Creative Commons Attribution (CC BY) license (https:// creativecommons.org/licenses/by/ $4.0 /)$.

\begin{abstract}
In Canada, there are three groups of Aboriginal people, also referred to as Indigenous peoples, and these include the First Nations, Inuit, and Métis. Although often thought of collectively, each has its distinct history, culture, and perspectives. The Métis people are mixed-culture people stemming from a long history of Indigenous people and European settlers intermixing and having offspring. Furthermore, the living history representing mixed ancestry and family heritage is often ignored, specifically within higher education. Dominant narratives permeate the curriculum across all levels of education, further marginalizing the stories of Métis people. I explore the experiences of Métis women in higher education within a specific region in Canada. Using semi-structured interview questions and written narratives, I examine the concepts of identity, institutional practices, and reconciliation as described by Métis women. Results assist in providing a voice to the Métis women's experiences as they challenge and resist colonial narratives of their culture and expand upon a new vision of Métis content inclusion in higher education as reconciliation.
\end{abstract}

Keywords: higher education; identity; Indigenous Content Requirements; institutional practices; Métis; reconciliation

\section{Introduction}

As a result of the final report of The Truth and Reconciliation Commission (2015) and its Calls to Action for education, many universities in Canada are working to design culturally appropriate curricula and to "Indigenize" their institutions. While the intention is to demonstrate reconciliation through institutional practices, rarely do these committees consider the university experiences of Indigenous, let alone Métis, students. Rarely do these reconciliation plans veer away from a pan-Indigenous homogenizing approach to Indigenous content, subsuming Métis and Inuit cultures into First Nations as one monolithic category. This study focusses on how Métis women's knowledge, culture, and experience need to be explicitly addressed and discussed as reconciliation in higher education. The study investigates the following question: How have university courses and learning experiences impacted Métis women's understanding of their identities, the role of Métis-Specific Knowledge, and perspectives on reconciliation in higher education?

Using The Canadian Encyclopedia (2007) definitions, "First Nations" describes the Indigenous people in Canada. The "Inuit" or "Inuk" are Indigenous people who mainly inhabit northern regions of Canada and have a distinct language and culture. The term "Métis" is used to describe people of mixed European and Indigenous ancestry. These are the three recognized Aboriginal peoples in Canada. Today, we use the term "Indigenous" in Canada to coincide with references made by other countries to describe their Indigenous people but note that their rights are reflected as "Aboriginal" people in the Canadian constitution.

The Métis live throughout many parts of Canada. According to the most recent Statistics Canada report (Statistics Canada 2016), 1,673,785 Aboriginal people lived in Canada in 2016, comprising $4.9 \%$ of the population. The most substantial increase in any of the Aboriginal groups that year was the Métis population, which accounted for 587,545 people. Ontario had the largest Métis population in Canada, with one-fifth of the total Métis population (Statistics Canada 2016). Among this population are Métis people who attended 
post-secondary institutions for further education and, according to Statistics Canada (2015a), in 2011, 55\% of the Métis population had post-secondary qualifications; $16 \%$ had a trade certificate, $23 \%$ had a college diploma, $4 \%$ had a university certificate or diploma (vs. a Bachelor's degree), and 12\% had a university degree (Statistics Canada 2015b).

Statistics Canada (2015b) also reports that stated barriers to Indigenous students' post-secondary education include lack of confidence, a feeling of unpreparedness, time constraints, courses not meeting learning needs, and financial costs. However, the report provides little specific information on Métis learners. In addition, there continues to be limited Métis content and perspectives in most Canadian university courses, especially in Indigenous studies curricula (Dorion and Prefontaine n.d., p. 5). There remains a need for more content concerning the history and perspectives of Métis people within the curriculum across all education systems (Kearns and Anuik 2015).

My research demonstrates that a Métis-specific wise-practices approach to including Métis content is mostly absent but greatly needed in the higher education curriculum. Through the creation of a Métissage-as-reconciliation framework, and as a Métis person, I argue that Métis perspectives woven into university courses is a critical step towards acknowledging the identities, history, and culture of Métis people while creating more equitable, diverse, and inclusive (EDI) practices for Métis and all students. If Canadian universities want to implement Indigenous initiatives and programs to advance reconciliation, then Métis perspectives must be included for any meaningful and authentic engagement, recognition, and retention of Métis learners. Métissage-as-reconciliation offers a curricular framework for representing Métis identity, respectfully including Métis-specific perspectives in course content, and understanding how decolonizing efforts can be attentive to the learning experiences of Métis people. Reconciliation through Métissage can ensure a more robust institutional effort to address the TRC's Calls to Action and support the growing demographic of Métis students in Canadian universities.

\subsection{Statement of Purpose}

Although the Métis and First Nations peoples have much in common, such as their dislocation from land, loss of language, inability to practice their culture, and assimilation into mainstream Canada through education, there have always been fundamental differences that remain in place today (Frideres 2008) - for example, variations in constitutional, legal, and treaty rights among the different Indigenous groups of people living in Canada (Voyageur and Calliou 2000) and a lack of understanding of Indigenous identity, including the differences in the cultures of First Nations, Inuit, and the Métis (Frideres 2008). Thus, this research differs from research on First Nations students' ways of knowing, their historical and contemporary struggles for equal access to education, and their acts of resilience to improve the quality of and cultural safety in school. Rather, my research focusses specifically on the experiences of the Métis in higher education (university) versus post-secondary (which includes both university and college).

Given the lack of research concerning Métis students in higher education, this research is a study designed to contribute knowledge from the voices and experiences of Métis women by honouring the Métis experience in higher education and by acknowledging the deep sense of connection that the Métis have to their unique culture. The purpose of the research is to examine how university courses and learning experiences impact Métis women's understanding of (i) their identities, (ii) the role of Métis-Specific Knowledge, and (iii) their perspectives on reconciliation in higher education.

\subsection{Research Rationale}

Although much research has focused on First Nations students' experiences within higher education in Canada (Kirkness and Barnhardt 1991), research on Métis students' experiences is sparse (Chartrand et al. 2006; Dion 2012; Paci 2011), and it thus constitutes a significant gap in the literature. Few researchers have explored Métis people's experiences in higher education. Dion (2012) has reviewed Métis content in education faculties in 
Ontario, while Kearns and Anuik (2015) have explored Métis curricular challenges and possibilities in the Ontario Ministry of Education's policies. Gaudry and Hancock (2012) have studied Métis pedagogy in post-secondary settings, including decolonizing Métis pedagogy that actively and directly honours the diversity of Métis experiences and perspectives. Yet, Gaudry and Hancock (2012) remind us that "the relationship of these [dominant] narratives with decolonizing Métis pedagogies is crucial yet somewhat occulted" (p. 9), meaning that Métis pedagogies are hidden or do not exist within higher and mainstream education systems and there is no place for the Métis voice. The dominant narratives refer to those that "reproduce systems of power and privilege in schools and society" (Bacon and Lalvani 2019, p. 378), and I suggest that these dominant narratives marginalize the narratives and experiences of Métis people. Therefore, the problem that this research addresses is the lack of Métis perspectives in higher education. Reconciliation efforts in education should be inclusive of Métis perspectives because all Canadians need to have the opportunity to learn Métis content and contribution as part of the overall narrative of Confederation in Canada.

\section{Discussion}

Through my research, I have developed a new conceptual framework that is multidimensional and comprises three core categories arising from the data-identity, institutional practices, and reconciliation-as a lived experience to be embedded into higher education policies, administration, recruitment, and operations. It is evident that these categories were deeply and personally related to the research participants, who were Métis learners and educators working in Ontario, Canada. In this way, each category helps to contribute to the higher education environment, in which having a Métis voice, though challenging, also holds positive future possibilities.

\subsection{A New Conceptual Framework: Métissage-as-Reconciliation}

Using the constant comparison approach, the data and literature were consistently examined in search of relatable themes until key categories were formed. The framework demonstrates relationships among the participants' experiences (as one data set) and my narrative (as a second data set) and how they relate to one another within the study. As I combined themes of Métis Knowledge and a wise-practice approach from the two data sources, I was reminded of the Métis sash and its intricate finger-woven technique to tell the story. The visual of the sash and emergent conceptual framework is represented below (see Figure 1).

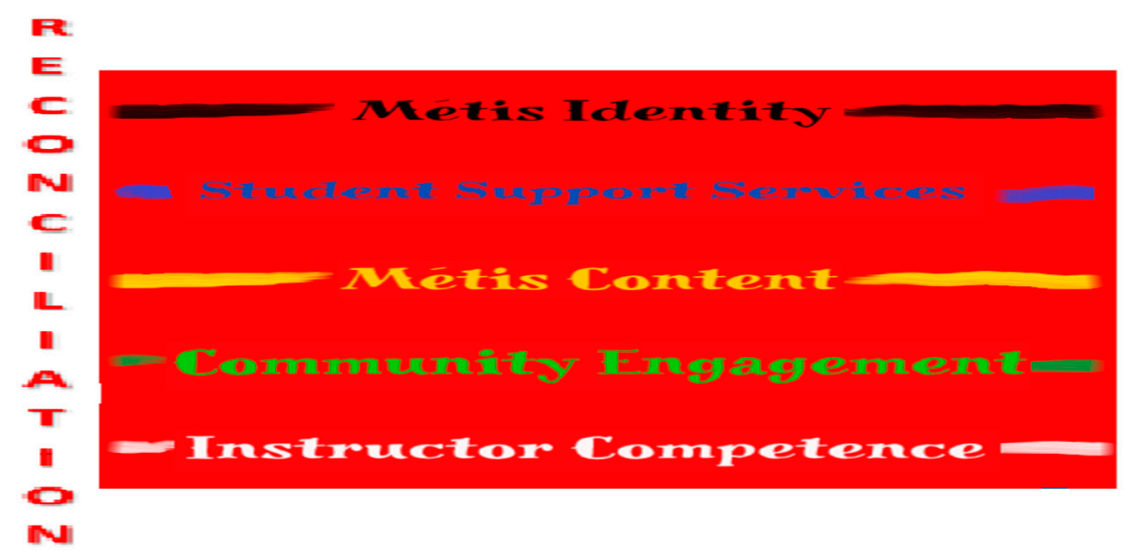

Figure 1. Métissage-as-reconciliation. Note. The Métissage-as-reconciliation framework is inclusive of the following elements: Métis identity, student support services, Métis content, community engagement, and instructor competence embedded within reconciliation.

The history of the sash (Vien and Barkwell 2011) includes understanding the sash as a piece of clothing symbolic of French-Canadian and Métis people's identity. Sashes were 
typically finger-woven out of nettle fiber, buffalo hair, or native hemp (Indigenous practice) and braided woolen garters (French-Canadian practice). Similarly, here, the sash uses the stories of Métis people's experiences and how they are affected by institutional practices as found in the colonized academy of higher education. The colours and patterns on sashes have varied over time, as does their creation in different parts of Canada. Historically, the colour black represented when the Métis were suppressed and dispossessed of their land by the government and the primary colour of the sash was traditionally red. Many Métis also refer to the shade of red as symbolic of the bloodshed throughout the resistances. The blue and white on the sash represent the Métis flag's colours that are contained in the infinity symbol; green represents fertility and growth, while yellow is symbolic of prosperity. Today, the Order of the Sash ceremony is the highest honour bestowed upon the Métis by many organizations.

\subsection{Red, Blue, Yellow, White, Green, Black}

To use the sash colours as representative of key categories within the conceptual framework, I use the primary shade of red to represent reconciliation. Reconciliation is woven throughout as the central underlying theme of the framework. Reconciliation is represented by the relationships that the Métis students have within the university and the university's desire to include Métis perspectives within it. Blue, yellow, white, and green colours represent the concepts of student support services, instructor competence (skills, knowledge, and attitudes), community engagement, and Métis content (historical perspectives and contemporary realities). These are the sash's colourful threads (emergent categories from the data sets); each holds significance and uniquely contributes to the layers within the framework.

Although the sash image does not contain a great deal of black, I propose this colour as it relates to Métis identity. Understanding Métis identity has played a significant role within the research. Although the time has passed where Métis people were suppressed and dispossessed from their land, I see the darkness of that history represented in the colour black. As Métis identity remains questioned and not understood, this darkness adds to the representation of the lack of acceptance of Métis identity within higher education. There is work for everyone to contribute to gain a thorough understanding of the cultural, legal, and political aspects of Métis identity.

These beautiful, colourful strands are woven together, and each strand in its place is required to create a unique and complete garment; the sash looks damaged when a stray piece of yarn is pulled from within it. With this image, the concepts of the two data sets (students support services, instructor competence, community engagement, Métis content, and identity) are brought together and interwoven as parts of a whole. Métissageas-reconciliation is achieved when all strands are addressed equally within the institution. The two data sets allow for the mixing of my narrative with that of the experiences of the research participants, forming a rich story to move towards reconciliation with Métis people within higher education.

While the academic program, graduation dates, and educational experiences may have differed for each participant, each of the three common categories (identity, institutional practices, and reconciliation) were prominent factors amongst the Métis participants and created valuable contributions to this study. These categories (or themes) have dynamic dimensions: they highlight elements of education that were essential to each participant based on their experiences in higher education and their identity as Métis people. Similarly, the themes of Indigenization, curriculum and pedagogy, professional development, and cultural safety are essential components when looking further into mandatory Indigenous content courses and institutional practices. These elements are woven together in the new conceptual framework proposed to include the important elements required to actively engage in Métissage-as-reconciliation within higher education. 


\subsection{A Métissage-as-Reconciliation Conceptual Framework in Education}

There is a lack of formal literature that defines Métis Knowledge as a worldview. Macdougall (2017) states that "through extensive kinship networks and shared experiences, Métis people interacted with the natural and spiritual world that reflected their worldview, which included a profound shared sense of mutual responsibility for each other" (p. 9). A generalized approach to the Métis worldview is prevalent as "much of Métis worldview contains philosophy and beliefs learned from their First Nations relations" (Dorion 2015, p. 4). This worldview is not helpful for Métis women wanting to research and write through a Métis lens. This study's conclusion demonstrates that a Métis-Specific Knowledge approach is absent from the post-secondary curriculum because there is no "singularly identifiable Métis worldview" (Lowan-Trudeau 2014, p. 353; Gibbs 2000; Richardson 2004). My study defines Métis Knowledge as an understanding of Métis history. It is an awareness of Métis people's political and constitutional rights that play out in how a person identifies themselves, noting the contention throughout Canada on who can claim Métis identity. Further, it is an understanding of the Métis way of life concerning cultural practices and traditions. Métis Knowledge grounds a Métis person in their historic community and extended family relations. It is critical that Métis Knowledge can be presented in classes where worldviews and perspectives on Indigenous research methods are taught and discussed as an option for those students wanting to incorporate a Métis-specific lens within their work. Métissage-as-reconciliation needs to continue to build upon and challenge the places within the academy where there is an absence of Métis-specific perspectives.

Furthermore, reconciliation in education with Métis people is not clearly defined, so introducing a Métissage-as-reconciliation conceptual framework is appropriate. Tuhiwai-Smith (2007) has argued that "an important task of Indigenous research in 'becoming' a community of researchers is about capacity building, developing and mentoring researchers, and creating the space and support for new research approaches to research and new examinations of Indigenous knowledge" (p. 122). Allowing for a Métis-specific conceptual framework in higher education would support Métis students in using a culturally relevant academic tool. Indigenous researchers actively seek ways to disrupt "the history of exploitation, suspicion, misunderstanding, and prejudice" (Rigney 1999, p. 117) of Indigenous people worldwide. This approach would help to privilege Indigenous Knowledges, while also creating Indigenous methodologies and approaches to research (Tuhiwai-Smith 2007, p. 116). Implementing the proposed Métissageas-reconciliation conceptual framework would expand and include more Métis voices to be contextualized within the scope and practice of Métis research.

One of the key findings of this research was that Métis Knowledge can be used in an exploratory manner: as a research method, methodology, and conceptual framework. Further research can explore and expand on these ideas. The development of a MétisKnowledge research approach must be supported as an "acceptable" or trustworthy and recognizable form of Indigenous research within the academy. As the presence of academic Indigenous researchers (Absolon 2011; Kovach 2009; Wilson 2008) and the number of Indigenous and Métis scholars in Canadian universities continue to grow, Métis Master's and Doctoral students must fit their research methodology and methods into either Western or Indigenous (primarily First Nations) approaches. Donald (2012) has used "Métissage as a decolonizing research sensibility" to connect historic and contemporary Indigenous people and Canadians within a decolonizing context (p. 534). Lowan-Trudeau (2012) has developed an approach that he has termed methodological Métissage, combining Indigenous and interpretive traditions for research in Canadian environmental education (p. 113). However, specifically in faculties of education, there is no Métis conceptual framework that is recognizable, discussed, or taught within higher education. As Métis researchers continue to work towards a model of research for their people and with Métis communities, this lack of a Métis-specific set of principles or conceptual framework needs to be demonstrated and opened up to Métis perspectives to improve the academic freedom and environment to research from within a Métis worldview. A Métis-specific 
conceptual framework adds a culturally reflective approach of the Métis people and advances Indigenous research in Canada.

\section{Results}

Consistent with Métissage-grounded theory methodology, three phases of data analysis were employed: open coding, selective coding, and theoretical coding. One hundred and thirty-five codes emerged from the open coding of the interviews and questionnaires. Constant comparison analysis was exercised using the NVivo software to discover selective codes. Additional constant comparison analysis was used to discover the relationships between the open and selective codes, leading to three main categories: identity, institutional practices, and reconciliation (see Table 1). As the main categories emerged from the data collection coding processes, they highlighted the participants' learning experiences in higher education as Métis women. The emergence of Métis Knowledge as the core category — and main theme-demonstrates the prevalent attributes affecting the experience of Métis women enrolled in higher education. The following summarizes the codes as they were condensed through the constant comparison method, resulting in the following three main categories, and resulting sub-categories of data.

Table 1. Categories and sub-categories.

\begin{tabular}{ccc}
\hline Métis Identity & Institutional Practices & Reconciliation \\
\hline Physical appearance & Cultural visibility & Truth-telling \\
Constitutional rights & Student support services & Voice \\
& Safe and welcoming spaces & Self-identification processes \\
& University barriers & \\
& & \\
\hline
\end{tabular}

\subsection{Métis Identity}

Métis identity within its cultural, political, and legal contexts needs to be defined and discussed when Indigenous content is presented. This clarification speaks to the history of Métis people and the Métis community's contemporary realities today. Métis women are frustrated when others reference them as simply mix-blooded people without understanding the Métis ethnogenesis. Métis women are also frustrated with others not knowing about constitutional rights and the Supreme Court rulings that acknowledge the Métis as Aboriginal people in Canada who fall under federal jurisdiction. Métis women want to have a validated place within institutions of higher learning. Métis women believe that their university experiences are affected when their culture and history are pan-Indigenized. People talk fluently about First Nations, Inuit, and Métis people as if they share one history, one culture, one language, one worldview, and a single knowledge system, and this is not true. Métis women in higher education want to see their distinct culture, separate and unique from their First Nations and Inuit relations, represented within the academy, and this is specific to their history as Indigenous people in Canada being represented in the curriculum.

\subsection{Institutional Practices}

Within the institution, the Métis women want to be included, and this inclusivity comes from seeing the history of their people and culture reflected. Métis women also want to be welcomed to access various student support services in Indigenous student spaces. These spaces need to be inclusive of the Métis students, primarily because they self-identify through institutional practices. The areas need to be staffed with culturally aware and competent people who understand them as Métis students. Institutional practices reflect how the university sees and values its Métis students and how inclusive it is within their university spaces. The knowledge that others hold for Métis perspectives is crucial and greatly affects the Métis women's experience at universities. By Métis symbols and artifacts being visible on campus, a sense of belongingness is created. It is only appropriate that, as 
a distinct cultural group within Canada, the Métis culture is visible while engaging with institutional processes.

\subsection{Reconciliation}

Current institutional practices, which do not differentiate Métis identity from First Nations or Inuit identity, significantly impact the experiences that Métis students have in university education and affect their learning. In the spirit of reconciliation, Métis women want people to have a well-developed understanding of Métis identity, history, and perspectives. Métis female students wish others to understand that reconciliation in education is different for them as they have a different history in Canada as Indigenous people. The Métis women want the effects of the historical treatment and trauma that they endured by the government acknowledged, and this includes others knowing about Métis history, worldview, and knowledge systems. Non-Indigenous people need to let go of their prejudices and negative stereotypes of Métis people as these are felt and experienced by Métis women in educational institutions today and play out through racism, discrimination, and microaggressions. Reconciliation is an opportunity for truth-telling and for everyone to take responsibility for their role in Canada's history. Reconciliation can occur to move things forward with Métis students in education. Institutional staff, including instructors, are encouraged to authentically engage with the broader Métis community and traditional Knowledge Holders when including Métis perspectives to ensure that they are accurately depicted. Reconciliation is a time for building relationships, truth-telling, and allowing Métis voices and experiences to be a part of conversations within the academy.

\subsection{Including Métis Knowledge within Higher Education}

Historically, the government has enforced a racist lens and the attempted assimilation to what they thought to be civilization, making it necessary to question the moral aspects of education's foundation with regard to Métis and other Indigenous students in Canada. "Indigenous students have been part of a forced assimilation plan-their heritage and knowledge rejected and suppressed, and ignored by the education system" (Battiste 2013, p. 23): we need to advance this truth before we can make the necessary changes in higher education to address the Western dominant pedagogy, and with this, the experiences of Métis women need to be told and shared. "To be an anti-racist educator is to be a theorist and practitioner for change" (Dei 1996, p. 26); as an emerging Métis academic, I know that change is possible through a more culturally relevant, Métis-infused institution. Métis inclusion would allow students to see themselves reflected in the institution (curriculum, policies, and practices). Institutions need to reflect on their biases of Métis women while they cultivate new approaches to better support Métis learners. Métis pedagogies need to focus on Métis culture, to enable and empower Métis women who would otherwise remain on the margin of the classroom or be seen through a racist lens. By exposing these very important issues that Métis women students face, it is crucial for higher education institutions to find solutions in collaboration with Métis communities. I have developed a conceptual framework that focusses on Métissage-as-reconciliation within higher education, as a step towards reconciliation, and thus the creation of inclusive, diverse, and equitable practices within the academy that provide for Métis women experiences to be acknowledged.

While the integration of Indigenous Knowledge into university curriculum content is now considered critical for any reconciliation effort in higher education, Métis-specific content has been relegated to a secondary spot in university reconciliation, like the road allowance for people living on the periphery (Douaud 1983, p. 75). In a study supporting Métis learners and self-identification in post-secondary education in Ontario, Paci (2011) warns that there are limited opportunities for Métis students "to connect with their peers and to see their culture reflected in the curriculum" (p. 6); it is this lack of opportunity that must be avoided. Métis women deserve to see Métis content in mandatory Indigenous Content Requirement courses and in institutional processes as reconciliation efforts addressing the unique history and culture of the Métis people, rather than furthering a pan-Indigenous 
tokenism approach to content integration that students have had to settle for because the institution has not had the capacity to address their content approach.

\section{Materials and Methods}

The research follows a grounded theory approach of constant comparison within a Métissage design, where Métis storytelling is blended with autobiographical narratives and interview data. Twelve participants, all Métis women living in Ontario and involved in higher education, completed interviews or submitted written responses to semi-structured questions, either as students enrolled in a north-central university, as alumni working in education organizations, or as community members engaged in school systems.

The site for this study was a north-central university in Canada that has a mandated Indigenous Content Requirement course and a Department of Indigenous Learning. This university was selected because it is an area thriving with Indigenous peoples and Métis students were accessible. Overall, this site was identified as having potential to provide rich data regarding Métis participants: the university has approximately 8300 students across two campuses, and many full-time undergraduate students from north-central locations in Ontario.

\subsection{Grounded Theory Methodology and Métissage Methodology}

The intent of the study was to use grounded theory (Glaser and Strauss 1967) as the primary research methodology; however, as a Métis-specific research study, the inclusion of a Métissage research paradigm was required to assist in capturing the worldview as presented by the research participants. As a result, the qualitative research study grew to include the use of a blended methodology based on grounded theory (Glaser and Strauss 1967) and Métissage (Donald 2009). In line with a Métissage research paradigm, the combination of the European research methods of grounded theory and Indigenous methodology allows me to use both processes as a blended approach to conduct my research. This blended approach is much like my mixed culture: instead of choosing one Eurocentric research methodology or solely focusing on the limited Indigenous research methodologies available, I chose both. "Indigenous methodologies have been employed for generations, but because of colonization efforts to eradicate Native ways of knowing, they lost value in mainstream research" (Tachine et al. 2016, p. 282). Of note is that grounded theory has developed and emerged over time, but to implement and describe the data analysis related to this study, I used a combination of critical constructs as appropriate according to classic grounded theory (Glaser and Strauss 1967), modified grounded theory (Strauss and Corbin 1990), and constructivist grounded theory (Charmaz 2000) terminology.

\subsubsection{Grounded Theory Methodology}

Ground theory methodology originated with Glaser and Strauss' (1967) seminal work, The Discovery of Grounded Theory. Grounded theory is both a method and a methodology that "involves generating theory and doing social research [as] two parts of the same process" (Glaser 1978, p. 2). In grounded theory methodology, "theory may be generated initially from the data, or, if existing (grounded) theories seem appropriate to the area of investigation, then these may be elaborated and modified as incoming data are meticulously played against them" (Strauss and Corbin 1994, p. 273). Grounded theory methodology allows researchers to learn what they can from participants' interpretations and perspectives, and in turn, these become the researcher's conceptualizations (Strauss and Corbin 1994, p. 280). This methodology is best suited to my study of Métis women's perspectives in higher education. Grounded theory methodology also promotes exploring multiple aspects during the research inquiry (Strauss and Corbin 1994, p. 280). For this reason, I used the multiple perspectives of Métis students, alumni, additional community members, and my personal story. 


\subsubsection{Métissage Methodology}

Denzin (2007) has claimed that using a modified version of grounded theory with Indigenous research is essential "because of its commitment to critical, open-ended inquiry, [which] can be a decolonizing tool for Indigenous and non-Indigenous scholars alike" (p. 456). He has stated:

We are during a global social movement of involving anti-colonialist discourse.

This movement is evident in the emergence and proliferation of critical grounded Indigenous epistemologies and methodologies. These epistemologies are forms of critical pedagogy; they embody critical politics of representation. (p. 461)

The literature on Métissage as an Indigenous research methodology is underdeveloped, and my research contributes to the exploratory use of a Métissage methodology and thus represents one population of Métis peoples' experiences. According to Donald (2012), one main goal of Indigenous Métissage is "to enact ethical relationality as a philosophical commitment", where "ethical relationality is an ecological understanding of human relationality that does not deny difference, but rather seeks to understand more deeply how our different histories and experiences position us in relation to each other" (p. 535).

I used the Métissage approach to discuss ways to enhance Métis education, to further develop Métissage as a methodology, and to assist research participants in reclaiming Métis education through to a higher education lifelong learning model. This body of work strives toward a Métis higher-education conceptual framework that is specific to the Métis culture. I am aware of the limitations imposed by using Western research methodologies and that Indigenous research methodologies are not specific to the Métis people; hence, the use of a bricolage approach (i.e., utilizing what is available to me as the researcher) helped me to explore and embark upon a Métissage research methodology that reflects my research participants and myself as students in higher education. Tilley has (Tilley 2016) noted:

Analysis is a stage in the research process during which students need to understand and work against their limitations and consider returning to the literature (and other sources) in hopes of building historical and contextual understandings when needed. They have to take care not to continue with imperialist colonizing practices when their research involves Indigenous and/or marginalized individuals and populations. (p. 161)

A Métissage methodology was employed, inclusive of Métis perspectives and Métis women's voices and experiences in higher education. As I consider research a personal experience deeply rooted within a blend of perspectives, and as the Métis women were positioned within a mixed worldview, a Métissage research methodology is relevant to my study.

\subsection{Data Analysis}

Participants' stories (one-on-one interview transcripts), questionnaires (written submissions), and my narrative were paired with key texts (meeting minutes, memos, and notes) and were used as data that were then explored through the grounded theory method approach. This method provided the flexibility to investigate the Métis participants' experiences without the constraints of research methods that could limit the research goals. The data were coded to bring forward common words used to describe the participants' perspectives and analyze their amalgamated experiences. Coding is a crucial feature of data collection in grounded theory: it "is an analytical process used to identify concepts, similarities, and conceptual reoccurrences in data ... and is a procedure for developing categories of information" (Tie et al. 2019, p. 4). It "is generally done for broad concepts and as new concepts arise", and thus a list was maintained to keep an ongoing record of codes (Savin-Baden and Major 2013, p. 189). Further, "coding is the pivotal link between collecting data and developing an emergent theory [conceptual framework] to explain these data; through coding, you define what is happening in the data and begin to grapple with what it means" (Charmaz 2014, p. 113). Coding the data allowed me to take all the 
data apart while finding commonalities and differences as "the purpose of this process is to count numbers of codes once the coding process is finished for all relevant data" (Kelle 2007, p. 193).

Each piece of data was coded separately and had its own set of codes; next, similar codes from each were highlighted, and comparisons were made. This process is referred to as the constant comparative method or the generation of a conceptual framework (Glaser and Strauss 1967), which is used to "make comparisons at each level of analytic work" (Charmaz 2014, p. 132). This method of the constant comparative technique "is used to find consistencies and differences, with the aim of continually refining concepts and theoretically relevant categories" (Tie et al. 2019, p. 4). The goal is to research to the point of saturation with the data-that is, to the point where no new information is gathered. I knew I had reached this point as a core category was identified, the data analysis failed to produce any new categories or themes, and I could not make any further relationships amongst the memos (Birks and Mills 2015).

Further, the categories are "constant[ly] compar[ed] to see if the data support and continue to support emerging categories ... the process further builds and substantiates the emerging categories by defining their properties and dimensions" (Holton 2007, p. 277) and where "properties refer to the characteristics that are common to all the concepts in the category and dimensions are the variations of the property" (Tie et al. 2019, p. 5). The constant comparison method continues throughout the coding process until a core category begins to emerge (Holton 2007, pp. 278-79). Categories "are referred to as theoretically saturated when new data analysis returns codes that only fit in existing categories, and these categories are sufficiently explained in terms of their properties and the dimensions" (Birks and Mills 2015, p. 10).

\subsection{TEMI and NVivo Software}

The software programs TEMI and NVivo were employed to aid with the data collection and analysis phase of the study. TEMI was used to record interviews and provide transcriptions of the text generated from the interviews. NVivo was used in the initial data coding process and later to create more significant categories and themes, as well as to sort the data. The word frequency feature was used to search for the key terms that aided in creating the categories and sub-categories. As categories and themes emerged, the mind-mapping feature of the software assisted in displaying the results in a condensed, visual image form.

\section{Conclusions}

The notion of an equitable, diverse, and inclusive environment for reconciliation within Canadian higher education must demonstrate validation of and access to Métis Knowledge. If Métis women are to believe in Canadian universities' investment, where Indigenous initiatives and programs are advertised as available and advancing reconciliation efforts is a stated priority, then there remains more work to be done to be inclusive of Métis people. The Métissage-as-reconciliation conceptual framework lays the foundation to develop: an awareness of how learning experiences impact Métis students' understanding of their cultural identities; the role of Métis-specific Knowledge in higher education; and perspectives on reconciliation. This study investigated Métissage as an exploratory research methodology, building upon the work of Donald (2012) and Lowan-Trudeau (2012). Métis students know that there is a great deal of work to be done within higher education to achieve the diversity, equity, and inclusion that they seek as Métis peoples to be included within the institution.

A deep commitment to change derives from relationships that are built on trust and this needs to be addressed with respect to how Métis people are responded to within the institution by instructors, staff, learners, and institutional processes. If reconciliation efforts are not supported by the institution, they are likely not to happen. Support towards reconciliation must be demonstrated through tangible actions with specific strategic initiatives in 
place, as well as safe spaces for Métis women on campuses, opportunities to come together to learn about Métis perspectives, and a focus on systemic inequities within institutions. Institutional practices need to be examined to ensure that Métis perspectives and people are engaged within the academy.

Wolfe (1999) posits that the elimination of Indigenous societies is the goal of settler colonies, where invasion is seen as a structure, not an event, and the colonizers come to stay (p. 2): "Elimination is not [based] on race (or religion, ethnicity, the grade of civilization, etc.) but access to territory" (Wolfe 2006, p. 388). In this case, the institution of higher education represents the territory. The academy has not been inclusive or kind to Métis people because it has primarily rejected Métis Knowledge and perspectives. Unrestricted by the colonizer's gaze or liberated from settler impositions, my research participants shared experiences on their continuous marginalization and silenced voices within the territory of the academy. Despite having to face hardships, trauma, deprivation, and assimilation as a people, coupled with the extinguishment of Métis rights and dispossession from land, the essence of their culture has lived. Fighting against exclusion, each research participant has successfully graduated from a university program and their acts of resilience and resistance do not go unnoticed.

The student experience for Métis women is different when institutions are willing to change. Métis people and institutions are aware that there is a great deal of work to be done within higher education to achieve the diversity, equity, and inclusion that the Métis people seek within the academy. Through my research, and weaving together the stories of Métis student experiences and institutional practices, I have demonstrated that Métissage-as-reconciliation is achievable and will benefit teaching and learning for all, especially when institutions are authentically engaging with bringing Métis perspectives into the academy. This work is challenging, and Métis community members must support and assist institutions as allies. Weaving the sash together requires Métis people and the academy to build relationships, founded on respect and reciprocity, that are generative and infinite.

Funding: This research received no external funding.

Institutional Review Board Statement: The study was approved by the Research Ethics Board of Lakehead University, Thunder Bay, Ontario, Canada (Romeo \#1464918).

Informed Consent Statement: Informed consent was obtained from all subjects involved in the study. This research was carried out in accordance with the Tri-Council Policy: Ethical Conduct for Research Involving Humans-TCPS 2 (2018).

Data Availability Statement: Not applicable.

Acknowledgments: In this section, you can acknowledge any support given which is not covered by the author contribution or funding sections. This may include administrative and technical support, or donations in kind (e.g., materials used for experiments).

Conflicts of Interest: The author declares no conflict of interest.

\section{References}

Absolon, Kathy. 2011. Kaandossiwin: How We Come to Know. Nova Scotia: Fernwood Publishing.

Bacon, Jessica, and Priya Lalvani. 2019. Dominant narratives, subjected knowledges, and the righting of the story of disability in k-12 curricula. Curriculum Inquiry 49: 387-404. [CrossRef]

Battiste, Marie. 2013. Decolonizing Education: Nourishing the Learning Spirit. Saskatoon: Purich Publishing.

Birks, Melanie, and Jane E. Mills. 2015. Grounded Theory: A Practical Guide, 2nd ed. Thousand Oaks: SAGE Publishing.

Charmaz, Kathy. 2000. Grounded theory: Objectivist and constructivist methods. In Handbook of Qualitative Research, 2nd ed. Edited by Norman K. Denzin and Yvonna S. Lincoln. Thousand Oaks: SAGE Publishing.

Charmaz, Kathy. 2014. Constructing Grounded Theory, 2nd ed. Thousand Oaks: SAGE Publishing.

Chartrand, Larry, Tricia E. Logan, and Judy D. Daniels. 2006. Métis History and Experience and Residential Schools in Canada. The Aboriginal Healing and Wellness Foundation. Available online: http:/ /www.ahf.ca/downloads/Metiseweb.pdf (accessed on 17 November 2020).

Dei, George. 1996. Anti-Racism Education: Theory and Practice. Nova Scotia: Fernwood Publishing. 
Denzin, Norman K. 2007. Grounded theory and the politics of interpretation. In The SAGE Handbook of Grounded Theory. Edited by Antony Brant and Kathy Charmaz. Thousand Oaks: SAGE Publishing, pp. 454-71.

Dion, Susan. 2012. Our Place in the Circle: A Review of Métis Content in Ontario Faculties of Education. York: York University.

Donald, Dwayne. 2009. Forts, curriculum, and Indigenous Métissage: Imaging decolonization of Aboriginal-Canadian relations in educational contexts. First Nations Perspectives 2: 1-24.

Donald, Dwayne. 2012. Indigenous Métissage: A decolonizing research sensibility. International Journal of Qualitative Studies in Education 25: 533-55. [CrossRef]

Dorion, Leah, and Darren Prefontaine. n.d. Métis Land Rights and Self-Government: Métis Scrip System in Canada. Available online: http:/ / www.Metismuseum.ca/media/db/00725 (accessed on 12 November 2020).

Dorion, Leah. 2015. Artist statement and biography. In Indigenous Presence. Edited by Margaret Kovach, Jeannine Carriere, Harpell Montgomery, Mary J. Barrett and Carmen Gilles. Saskatoon: Educational Foundations/Educational Administration, College of Education, University of Saskatchewan, Available online: https:/ / education.usask.ca/documents/profiles/kovach/IndigenousPresence-2014-Kovach-M-et-al.pdf (accessed on 17 November 2020).

Douaud, Patrick. 1983. Canadian Métis identity: A pattern of evolution. Anthropos 78: 71-88.

Frideres, James. 2008. Aboriginal identity in the Canadian context. The Canadian Journal of Native Studies 2: 313-42.

Gaudry, Adam, and Robert L. A. Hancock. 2012. Decolonizing Métis pedagogies in post-secondary studies. Canadian Journal of Native Education 35: 7-22.

Gibbs, Ellen Ann. 2000. The Changing Face of the Métis Nation. Unpublished Master's Thesis, University of Lethbridge, Lethbridge, AB, Canada. Available online: https:/ / opus.uleth.ca/handle/10133/117 (accessed on 5 November 2020).

Glaser, Barry, and Anselm Strauss. 1967. The Discovery of Grounded Theory: Strategies for Qualitative Research. New York: Aldine De Gruyter.

Glaser, Barry. 1978. Theoretical Sensitivity. San Francisco: Sociology Press.

Holton, Judith. 2007. The coding process and its challenges. In The Sage Handbook of Grounded Theory. Edited by Antony Bryant and Kathy Charmaz. Thousand Oaks: SAGE Publishing, pp. 265-89.

Kearns, Laura Lee, and Jonathan Anuik. 2015. Métis curricular challenges and possibilities: A discussion initiated by First Nations, Métis, and Inuit education policy in Ontario. Journal of the Canadian Association for Curriculum Studies 12: 6-36.

Kelle, Udo. 2007. The development of categories: Different approaches in grounded theory. In The SAGE Handbook of Grounded Theory. Edited by Antony Bryant and Kathy Charmaz. Thousand Oaks: SAGE Publishing, pp. 191-213.

Kirkness, Verna, and Ray Barnhardt. 1991. First Nations and higher education: The four R's—Respect, relevance, reciprocity, responsibility. Journal of American Indian Education 30: 1-15.

Kovach, Margaret. 2009. Indigenous Methodologies: Characteristics, Conversations, and Contexts. Toronto: University of Toronto Press.

Lowan-Trudeau, Greg. 2012. Methodological Métissage: An interpretive Indigenous approach to environmental education research. Canadian Journal of Environmental Education 17: 113-30.

Lowan-Trudeau, Greg. 2014. Considering ecological Métissage: To blend or not to blend? Journal of Experiential Education 37: 351-66. [CrossRef]

Macdougall, Brenda. 2017. Land, Family, and Identity: Contextualizing Métis Health and Well-Being. Prince George: National Collaborating Centre for Aboriginal Health.

Paci, Chris. 2011. Research on Effective Practices to Support Métis Learners Achievement and Self-Identification Project. Final Report. Ottawa: Métis Nation of Ontario, Available online: http:/ /www.Metisnation.org/media/222452/mno\%20pse\%20research\%20final\%20 report\%20\%20march\%2031\%202011\%20final\%20version.pdf (accessed on 5 November 2020).

Richardson, Catherine Lynn. 2004. Becoming Métis: The Relationship between the Sense of Métis Self and Cultural Stories. Unpublished doctoral dissertation, University of Victoria, Victoria, BC, Canada. Available online: https://dspace.library.uvic.ca/bitstream/ handle/1828/655/richardson_2004.pdf;sequence=1 (accessed on 5 November 2020).

Rigney, Lester-Irabinna. 1999. Internationalization of an Indigenous anticolonial cultural critique of research methodologies: A guide to indigenist research methodology and its principles. Wicazo SA Journal of Native American Studies Review 14: 109-21. [CrossRef]

Savin-Baden, Maggi, and Claire Howell Major. 2013. Qualitative Research: The Essential Guide to Theory and Practice. New York: Routledge Taylor and Francis Group.

Statistics Canada. 2015a. Aboriginal Identity of Person. Available online: https:/ / www23.statcan.gc.ca/imdb/p3Var.pl?Function= DECI\&Id=59224 (accessed on 25 October 2020).

Statistics Canada. 2015b. Education. Aboriginal Statistics at a Glance, 2nd ed. Available online: https://www150.statcan.gc.ca/n1/pub/ 89-645-x/2015001/education-eng.htm (accessed on 27 October 2020).

Statistics Canada. 2016. The Daily. Aboriginal Peoples in Canada: Key Results from the 2016 Census. Available online: https://www150 .statcan.gc.ca/n1/daily-quotidien/171025/dq171025a-eng.htm?indid=14430-3\&indgeo=0 (accessed on 25 October 2020).

Strauss, Anselm, and Juliet Corbin. 1990. Basics of Qualitative Research: Grounded Theory Procedures and Techniques. Thousand Oaks: SAGE Publishing.

Strauss, Anselm, and Juliet Corbin. 1994. Grounded theory methodology: An overview. In Handbook of Qualitative Research. Edited by Norman K. Denzin and Yvonna S. Lincoln. Thousand Oaks: SAGE Publishing, pp. 273-85.

Tachine, Amanda, Eliza Yellow Bird, and Nolan L. Cabrera. 2016. Sharing circles: An Indigenous methodological approach for researching with groups of Indigenous Peoples. International Review of Qualitative Research 9: 277-95. [CrossRef] 
The Canadian Encyclopedia. 2007. Indigenous Peoples in Canada. Available online: https://www.thecanadianencyclopedia.ca/en/ article/aboriginal-people (accessed on 22 October 2020).

The Truth and Reconciliation Commission. 2015. Truth and Reconciliation Commission: Calls to Action. Available online: http: // trc.ca/assets/pdf/Calls_to_Action_English2.pdf (accessed on 22 October 2020).

Tie, Ylona Chun, Melanie Birks, and Karen Francis. 2019. Grounded theory research: A design framework for novice researchers. SAGE Open Medicine 7: 1-8.

Tilley, Susan. A. 2016. Doing Respectful Research: Power, Privilege, and Passion. Nova Scotia: Fernwood Publishing.

Tuhiwai-Smith, Linda. 2007. On tricky ground: Researching the Native in the age of uncertainty. In The Landscape of Qualitative Research. Edited by N. K. Denzin and Y. S. Lincoln. Thousand Oaks: SAGE Publishing.

Vien, Louise, and Lawrence Barkwell. 2011. The History of the Métis Sash. Louis Riel Institute. Available online: http:/ www. Metismuseum.ca/media/document.php/14789.History\%20of\%20the\%20Metis\%20Sash.pdf (accessed on 15 November 2020).

Voyageur, Cora J., and Brian Calliou. 2000. Various shades of red: Diversity within Canada's Indigenous community. The London Journal of Canadian Studies 16: 103-18.

Wilson, Shawn. 2008. Research Is Ceremony: Indigenous Research Methodology. Nova Scotia: Fernwood Publishing.

Wolfe, Patrick. 1999. Settler Colonialism and the Transformation of Anthropology. London: Cassell.

Wolfe, Patrick. 2006. Settler colonialism and the elimination of the native. Journal of Genocide Research 8: 387-409. [CrossRef] 